\title{
OPTIMIZATION OF WEIGHT AND ELASTIC PROPERTIES FOR UNIDIRECTIONAL GLASS FIBER REINFORCED COMPOSITES
}

\author{
Mortda Mohammed Sahib Al-Hamzawi \\ PhD student, University of Miskolc, Institute of Machine and Product Design \\ 3515 Miskolc, Miskolc-Egyetemváros, e-mail: mortdamohammed@gmail.com \\ Szabolcs Szávai \\ associate professor, University of Miskolc, Institute of Machine and Product Design \\ 3515 Miskolc, Miskolc-Egyetemváros, e-mail: szavai.szabolcs@uni-miskolc.hu
}

\begin{abstract}
Glass fibers reinforcing composites (GFRC) are the most common industrial materials due to their low weight and superior strength. Microstructure modeling provides a practical approach for predicting the behavior of the composite based on the constituent's property. The weight and mechanical properties of composite materials play a significant role in various applications such as aviation, marines, and vehicles industries. In this study, a microstructure model of (GFRC) is developed for a multi-objective optimization problem involving trade-offs between weight minimizing and material stiffness-enhancing. A finite element model of a representative volume element (RVE) of a material's microstructure is used to predict the elastic properties of the fiber and the matrix composites. Composite properties such as elasticity and density can be obtained directly from the RVE and extrapolated to a larger scale. The representative volume element $(R V E)$ is generated by using commercial software (Abaqus); then, the non-GUI mode is called by Isight Software to solve multi-objective optimization by using Archive based Micro Genetic (AMGA) Algorithm to obtain optimum design of composite $R V E$.
\end{abstract}

Keywords: Optimization, RVE, composite materials, AMGA Algorithm

\section{Introduction}

Due to the high stiffness-to-density ratio, the Fiber Reinforced Composites (FRC) are getting rapidly interesting for a wide variety of industries compared to non-reinforced polymers. In addition, a polymeric matrix and continuous fibers have great relevance and significance due to their excellent mechanical properties, good thermal stability and low density (Kammoun et al., 2011; Li et al., 2019). To obtain efficient and optimized designs, the ability to quantitatively predict the behavior of FRCs is crucial. To do this, and in particular to capture the influence of various microstructural parameters of FRCs that affect their macro-mechanical behavior, it is essential to use micromechanical-based models. Therefore, many studies have been conducted on this topic (Ekşi and Genel, 2017; Tian et al., 2015; Wang et al., 2011; Cai and Jin, 2018). The finite element method can directly reflect the structural characteristics of composite materials and construct the relationship between micromechanics and macroscopic mechanics when subjected to actual force or complex surfaces (Qi et al., 2019).

S. Z. H. Shah et al. developed a two-step methodology to predict the elastic constants of 3D fiberreinforced composites, and they used analytical and numerical methods to ascertain the accuracy of 
predicted elastic constants (Mentges et al., 2021). Elsayed Fathallah et al. Investigated optimization of minimizing the buoyancy factor submersible pressure hull by changing the angle of fiber orientation and ply thickness (Fathallah et al., 2015). Lars Bittrich et al. introduced the local optimization approach of both fiber angle and intrinsic thickness build-up of curvilinear fiber-reinforced composites (Bittrich et al., 2019). Mehdi Kalantari et al. produced a multi-objective analysis for unidirectional S-2 glass and T700S carbon fiber reinforced epoxy hybrid composites to maximize the flexural strength and minimize the weight and cost (Kalantari et al., 2016).

D. A. Saravanos and C. C. Chamist have developed a multi-objective optimal design methodology for lightweight, low-cost composite structures to improve dynamic performance and minimize damping resonance amplitudes (Saravanos and Chamis, 1992).

This paper aims to achieve multi-objective optimization involving density(weight) reduction and maximize longitudinal modulus elasticity (E11). The AMGA algorithm under the isight software environment has been used.

\section{Finite Element modeling}

\subsection{Modelling Representative Volume Element}

The RVE term was first used by Hill (Hill, 1963) and it can be defined as the smallest material volume element for which the macroscopic constitutive representation is a sufficiently accurate model to represent mean constitutive response (Omairey et al., 2019). Therefore, The RVE method cuts off a RVE from the whole periodic structure, applies specific unit displacement or force boundary conditions, and finds effective properties by making its strain energy equivalent with homogeneous material (Drugan and Willis, 1996).

A finite element model is established at the microscopic level to predict the macroscopic mechanical properties using a representative volume element (RVE). The pricipal of obtianing homgnouse propeties are illsutrated in figure (1). The RVE has been considered a unit cell under periodic boundary conditions, as shown in figure (1 left). Materials like fiber-reinforced composites are generally represented as a repeated array of periodic structures, as shown in figure (1 middle). Periodic Boundary Condition implies that each RVE has the same deformation and there is no separation between the neighboring RVE's. For a cubical RVE, the displacement on the pair of opposite surfaces is given by equations (1) and (2) (Siddharth and Ramesh, 2019).

$$
\begin{aligned}
& u_{i}^{j+}=\varepsilon_{i j} x_{i}^{j+}+u_{i}^{*} \\
& u_{i}^{j-}=\varepsilon_{i j} x_{k}^{j-}+u_{i}^{*}
\end{aligned}
$$

where $\mathrm{i}$ and $\mathrm{j}$ are the coordinate of the unit cell $(\mathrm{i}, \mathrm{j}=1,2,3)$, the indices $\left(j^{+}\right)$and $\left(j^{-}\right)$identify the pair of two opposite parallel boundary surfaces of a RVE. The $u_{i}^{*}$ is same at two parallel boundaries due to periodicity; therefore, the difference between the above two equations is

$$
u_{i}^{j+}-u_{i}^{j-}=\varepsilon_{i j} l_{i}
$$

where $\left(l_{i}\right)$ is the length of the unit cell. 


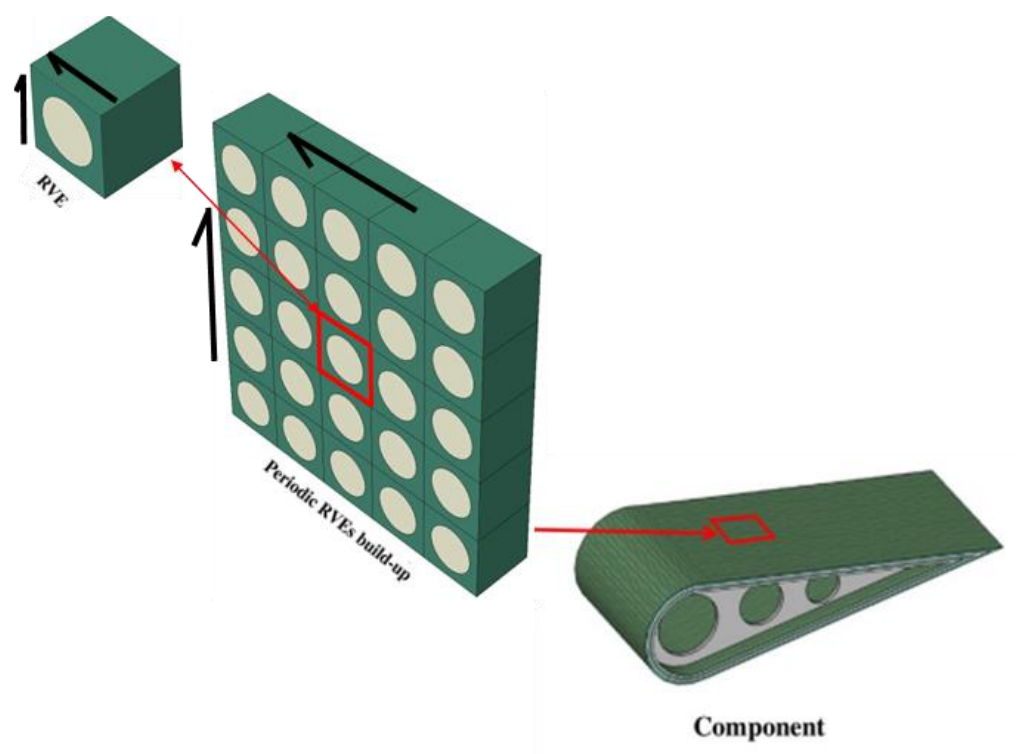

Figure 1. Illustration of periodical RVEs and large scale maertial build-up.

The homogenization based on periodic boundary condition is done using the micromechanics plugin in Abaqus. The RVE is subject to six different strains, including three normal tractions to obtain E11, E22 and E33, whereas the other three are shear deformations to obtain G12, G13 and G23. The strains were applied individually using periodic boundary conditions equation (3) (Garoz et al., 2019); The fibers are unidirectional and aligned along the (1) axis of the geometry of RVE. Figure (2) is the modeling geometry and associated meshing in commercial finite element solver ABAQUS.

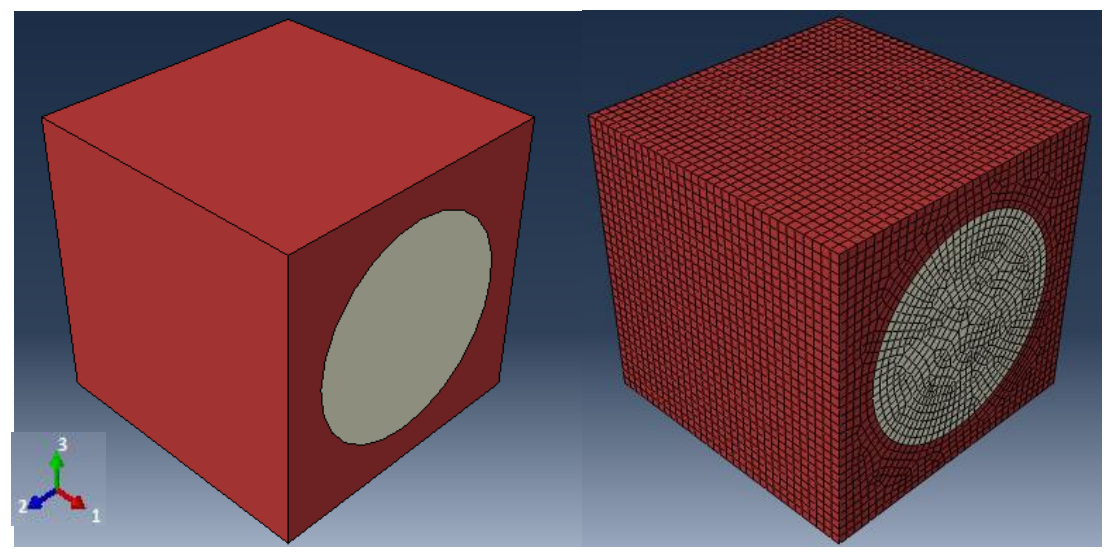

Figure 2. Finite element RVE.

\subsection{Materials}

The materials used for the homogenization are glass fiber reinforced polymers composite. The matrix and reinforcements' material properties are considered isotropic materials. The elastic constants and densities have been taken in range cover common types of glass fibers and matrices (Žmindák and Dudinský, 2012; Srivastava and Lal, 1991; Pal and Riyazuddin Haseebuddin, 2012; Mirkhalaf et al., 
2020; Sorini et al., 2016; Kimura et al., 2006). The properties of the constituent's material are listed in the table (1).

Table 1. Design variables of composite RVE

\begin{tabular}{|c|c|c|c|c|c|}
\hline & \# & Parameter & Description & Value & Unit \\
\hline \multirow{3}{*}{ 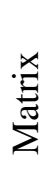 } & 1 & $\mathrm{E}_{\mathrm{m}}$ & Matrix Modulus of elasticity & $1600-5350$ & $\mathrm{MPa}$ \\
\hline & 2 & $V_{\mathrm{m}}$ & Matrix Poisson's ratio & $0.34-0.4$ & - \\
\hline & 3 & $\rho_{\mathrm{m}}$ & matrix density & $0.9-1260$ & $\mathrm{~g} / \mathrm{cc}$ \\
\hline \multirow{3}{*}{ 这 } & 1 & $\mathrm{E}_{\mathrm{f}}$ & Fiber Modulus of elasticity & $68900-86900$ & $\mathrm{MPa}$ \\
\hline & 2 & $v_{\mathrm{f}}$ & Fiber Poisson's ratio & $0.14-0.276$ & - \\
\hline & 3 & $\rho_{\mathrm{f}}$ & Fiber density & $2.44-2.7$ & $\mathrm{~g} / \mathrm{cc}$ \\
\hline
\end{tabular}

\section{Multi-objective optimization}

Optimization methodology is applied in most engineering and science branches. The Optimization process is concerned with selecting the best solution from a wide range of possible solutions so that the chosen solution is better than the rest in certain aspects. In recent years, multi-objective optimization has become popular, and many algorithms for solving multi-objective optimization problems have been proposed. Multi-objective optimization algorithms have gained wide acceptance because the quick computation of approximate solutions is often desirable for most engineering problems (Velden, 2010).

In this study, Isight software is used to drive the optimization process through call Software Abaqus using the no GUI mode. Archive-based Micro Genetic Algorithm (AMGA) has been specified to find optimum elastic properties and lighter weight of finite element RVE. AMGA is an evolutionary optimization algorithm and relies on genetic variation operators for creating new solutions. The generation scheme used in this algorithm is generational because only solutions created before that iteration (generation) are considered in the selection process during that iteration (generation). However, the algorithm generates a small number of new solutions at each iteration and can therefore also be classified as an almost steady-state genetic algorithm. The algorithm works with a small population size and keeps an external archive of obtained good solutions. A small number of solutions are generated using genetic variation operators at each iteration. The algorithm is referred to as an Archive-based Micro Genetic Algorithm (AMGA) because it works with a very small population size and uses an archive to maintain its search history. The best results are obtained if the size of the Archive is the same as the number of function evaluations allowed (i.e., the algorithm stores its complete search history) (Tiwari et al., 2008). The technique for solving the algorithm and the programming code is beyond this paper's scope, and we recommend reading reference (Sorini et al., 2016) for more details.

In this work, longitudinal elastic modulus (E11) is considered as a maximization optimization problem; however, the density of overall RVE (i.e., weight) is a minimization optimization problem. The design variables for optimization problems have been listed in the table(1). The longitudinal modules are calculated with updated design variables by the Abaqus micromechanics plugin and feed simultaneously to the optimization tool in isight as objective. Also, the overall density of RVE (composite) 
can be calculated under isight environment and specify as an objective function during the optimization process. So that, the density objective function and constraints can be formulated as below:

Density objective function (Tam et al., 2012).

$$
\rho_{c}=\rho_{f} f+(1-f) \rho_{m}
$$

The both objectives are Subjected to

$$
\begin{gathered}
6 \leq d \geq 9 \mu m \\
f \leq 0.6
\end{gathered}
$$

(d) and (f) are fiber diameter and fiber volume fraction, respectively.

\section{Results and discussion}

The objective optimization involves weight reduction and increasing the longitudinal stiffness $\left(\mathrm{E}_{11}\right)$ of composite materials at the microstructure level. The AMGA optimization algorithm has driven a nu-

\begin{tabular}{|c|c|c|c|c|c|c|c|}
\hline \multirow{9}{*}{ 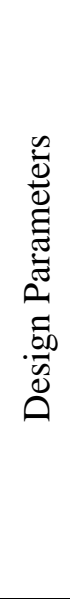 } & Parameter & Value & Unit & \multirow{6}{*}{ 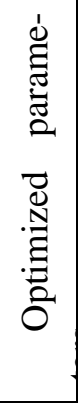 } & Parameter & Value & Unit \\
\hline & $\mathbf{E}_{\mathrm{f}}$ & 86314.83 & $\mathrm{MPa}$ & & E11 & 37120.90 & $\mathrm{MPa}$ \\
\hline & $\mathrm{E}_{\mathrm{m}}$ & 1710.56 & $\mathrm{MPa}$ & & $\rho_{\mathrm{c}}$ & 1590 & $\mathrm{~kg} / \mathrm{m}^{3}$ \\
\hline & $\rho_{\mathrm{f}}$ & 2610 & $\mathrm{~kg} / \mathrm{m}^{3}$ & & E22 & 5358.84 & $\mathrm{MPa}$ \\
\hline & $\rho_{\mathrm{m}}$ & 920 & $\mathrm{~kg} / \mathrm{m}^{3}$ & & $\mathrm{G} 12 / 13$ & 1450.07 & $\mathrm{MPa}$ \\
\hline & $v_{\mathrm{f}}$ & 0.27 & - & & G23 & 1132.61 & $\mathrm{MPa}$ \\
\hline & $v_{\mathrm{m}}$ & 0.40 & - & & & & \\
\hline & $\mathrm{d}$ & 7.12 & $\mu \mathrm{m}$ & & & & \\
\hline & $\mathrm{f}$ & 0.40 & - & & & & \\
\hline
\end{tabular}
merical RVE model with a range of design variables (as detailed in table 1).

Table 2. Best possible result for the constrained problem

The optimization process results in this study are listed in Table 2, which includes the design parameters that give the best-required objectives. The minimum density of composite RVE is $1.593 \mathrm{~g} / \mathrm{cc}$. However, the longitudinal stiffness is $37120.88 \mathrm{MPa}$. Figure (3) showed the feasible design points obtained by the optimization algorithm, also the optimum point which offers a trade-off between composite density and longitudinal stiffness is recognized (pink point) and it is corresponding to fiber diameter(d) value $\approx 7 \mu \mathrm{m}$. Figure (4) showed that the longitudinal stiffness $\left(\mathrm{E}_{11}\right)$ strongly correlates with fiber stiffness, Whereas; the matrix stiffness has a small contribution due to the fiber aligned in the longitudinal direction. 


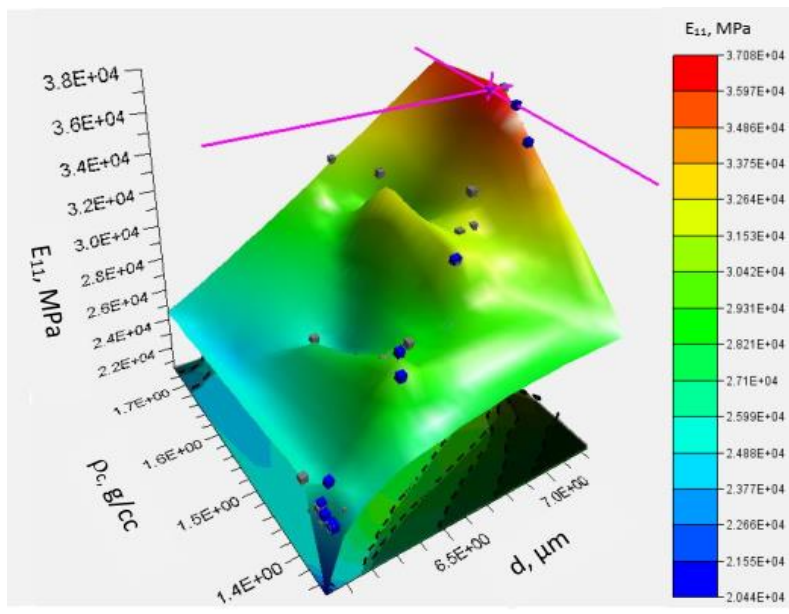

Figure 3. Feasible points surface.

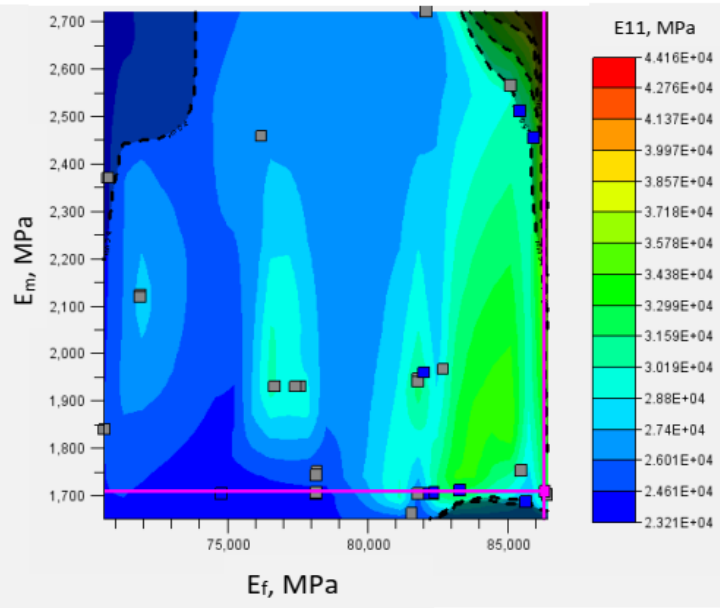

Figure 4. $E_{11}$ vs. matrix and fiber modulus.

Figures (5), (6), and (7) depicted transverse modulus of elasticity $\left(\mathrm{E}_{22} / \mathrm{E}_{33}\right)$, in plan $\left(\mathrm{G}_{12} / \mathrm{G}_{13}\right)$, and out plane shear modulus's $\left(\mathrm{G}_{23}\right)$ with matrix stiffness and fiber stiffness, as it can be seen that transverse elastic properties have been increased rapidly with matrices modulus. It can be concluded that the $\mathrm{Em}$ has the most influence on them in contrast to Ef. The values of $\mathrm{E}_{22} / \mathrm{E}_{33}, \mathrm{G}_{12}, \mathrm{G}_{13}$, and $\mathrm{G}_{23}$ at optimum design point were $5358.84 \mathrm{MPa}, 1450.07 \mathrm{MPa}$, and 1132.61MPa respectively.
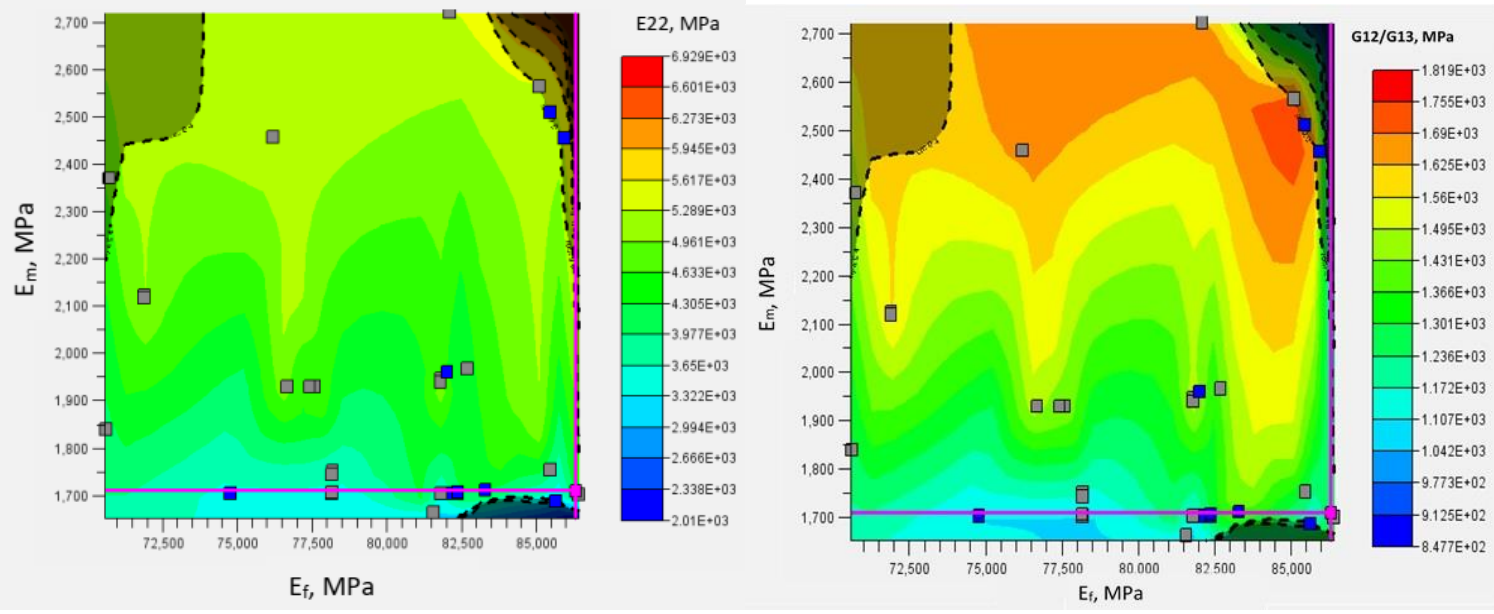

Figure 5. $E_{11} / E_{22} v$ s. matrix and fiber modulus. Figure 6. $G_{12} / G_{13} v s$. matrix and fiber modulus.

Figure (8) showed the overall composite material density distribution over specified ranges of matrix and fiber densities. The constituent's densities have the same influence approximately, and they are correlated with composite density in the same manner. The optimization algorithm pointed out the best density (pink point) in considering the longitudinal elastic modulus $\left(\mathrm{E}_{11}\right)$. 


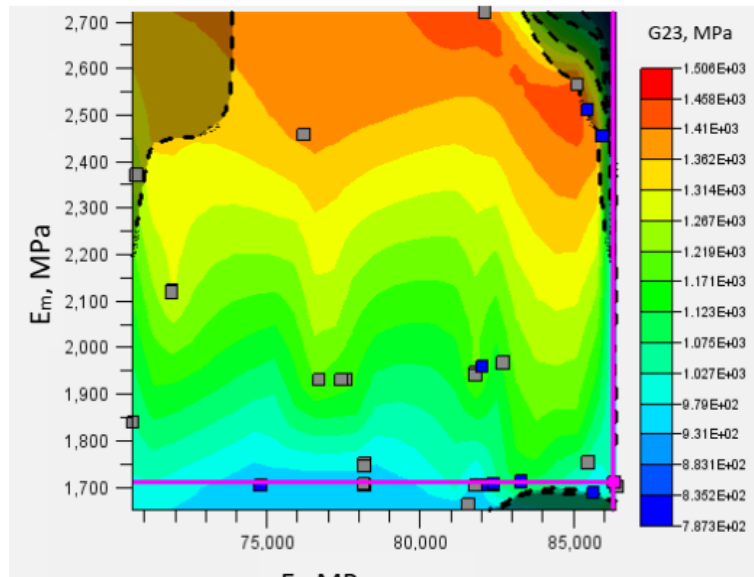

Ef. MPa

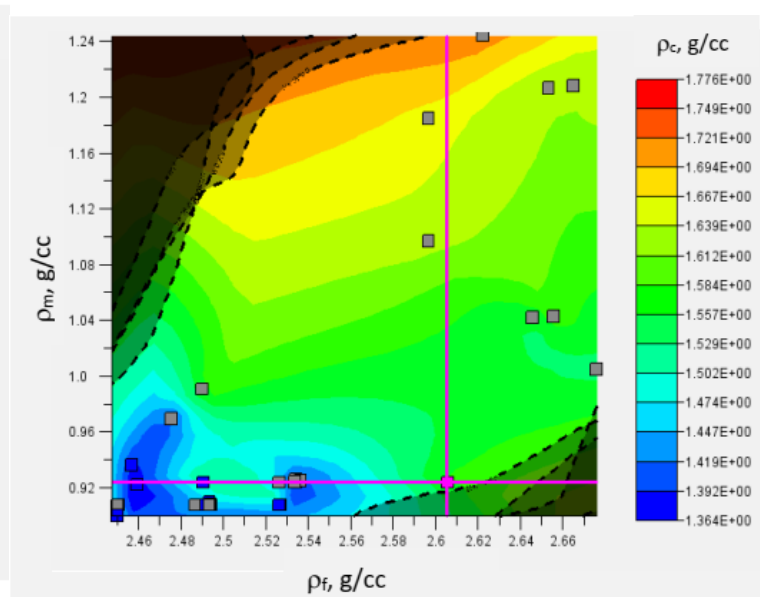

Figure 8. Composite density distribution.

Figure 7. $G_{12} / G_{13}$ vs. matrix and fiber modulus.

\section{Conclusions}

In this study, an approach for optimizing short glass fiber reinforced composite is proposed based on micromechanical structure. The optimization process involved a multi-objective problem that minimized the density of RVE and improving the longitudinal modulus $\left(\mathrm{E}_{11}\right)$. The AMGA optimization algorithm has been used along with a wide range of design variables. The optimization algorithm captured the optimum design parameters and reached a fair point between density (weight) and mechanical properties. The obtained results can be extrapolated to large-scale composite materials toward developing ultra-lightweight with reasonable computational cost.

\section{References}

[1] Kammoun, S., Doghri, I., Adam, L., Robert, G., and Delannay, L. (2011). First pseudo-grain failure model for inelastic composites with misaligned short fibers. Compos. Part A Appl. Sci. Manuf., 42(12), 1892-1902. https://doi.org/10.1016/j.compositesa.2011.08.013

[2] Li, Y. et al. (2019). Theoretical modeling of the temperature dependent tensile strength for particulate-polymer composites. Compos. Sci. Technol., 184, 107881. https://doi.org/10.1016/j.compscitech.2019.107881

[3] Ekşi, S., Genel, K. (2017). Comparison of mechanical properties of unidirectional and woven carbon, glass and aramid fiber reinforced epoxy composites. Acta Phys. Pol. A, 132(3), 879882. https://doi.org/10.12693/APhysPolA.132.879

[4] Tian, W., Qi, L., Zhou, J., Liang, J. and Ma, Y. (2015). Representative volume element for composites reinforced by spatially randomly distributed discontinuous fibers and its applications. Compos. Struct., 131, 366-373.

https://doi.org/10.1016/j.compstruct.2015.05.014

[5] Wang, X., Zhang, J., Wang, Z., Zhou, S. and Sun, X. (2011). Effects of interphase properties in unidirectional fiber reinforced composite materials. Mater. Des., 32(6), 3486-3492. https://doi.org/10.1016/j.matdes.2011.01.029

[6] Cai, R., Jin, T. (2018). The effect of microstructure of unidirectional fibre-reinforced composites on mechanical properties under transverse loading: A review. J. Reinf. Plast. 
Compos., 37(22), 1360-1377. https://doi.org/10.1177/0731684418796308

[7] Qi, Z., Zhang, N., Liu, Y. and Chen, W. (2019). Prediction of mechanical properties of carbon fiber based on cross-scale FEM and machine learning. Compos. Struct., 212(December 2018), 199-206. https://doi.org/10.1016/j.compstruct.2019.01.042

[8] Mentges, N., Dashtbozorg, B. and Mirkhalaf, S. M.(2021). A micromechanics-based artificial neural networks model for elastic properties of short fiber composites. Compos. Part B Eng., 213, 108736. https://doi.org/10.1016/j.compositesb.2021.108736

[9] Fathallah, E., Qi, H., Tong, L. and Helal, M. (2015). Design optimization of lay-up and composite material system to achieve minimum buoyancy factor for composite elliptical submersible pressure hull. Compos. Struct., 121, 16-26.

https://doi.org/10.1016/j.compstruct.2014.11.002

[10] Bittrich, L., Spickenheuer, A., Almeida, J. H. S., Müller, S., Kroll, L. and Heinrich, G. (2019). Optimizing Variable-Axial Fiber-Reinforced Composite Laminates: The Direct Fiber Path Optimization Concept. Math. Probl. Eng., 2019. https://doi.org/10.1155/2019/8260563

[11] Kalantari, M., Dong, C. and Davies, I. J. (2016). Multi-objective analysis for optimal and robust design of unidirectional glass/carbon fibre reinforced hybrid epoxy composites under flexural loading. Compos. Part B Eng., 84, 130-139.

https://doi.org/10.1016/j.compositesb.2015.08.050

[12] Saravanos D. A. and Chamis, C. C. (1992). Multiobjective shape and material optimization of composite structures including damping. AIAA J., 30(3), 805-813.

https://doi.org/10.2514/3.10988

[13] Hill, R. (1963). Elastic properties of reinforced solids: Some theoretical principles. J. Mech. Phys. Solids, 11(5), 357-372. https://doi.org/10.1016/0022-5096(63)90036-X

[14] Omairey, S. L., Dunning, P. D. and Sriramula, S. (2019). Development of an ABAQUS plugin tool for periodic RVE homogenisation. Eng. Comput., 35(2), 567-577.

https://doi.org/10.1007/s00366-018-0616-4

[15] Drugan W. J. and Willis, J. R. (1996). A micromechanics-based nonlocal constitutive equation and estimates of representative volume element size for elastic composites. J. Mech. Phys. Solids, 44(4), 497-524. https://doi.org/10.1016/0022-5096(96)00007-5

[16] Siddharth S. and Ramesh, A. (2019). Homogenization of mechanical properties of unidirectional fibre reinforced composites with matrix and interface defects: A finite element approach. J. Phys. Conf. Ser., 1355(1). https://doi.org/10.1088/1742-6596/1355/1/012040

[17] Garoz, D., Gilabert, F. A., Sevenois, R. D. B., Spronk, S. W. F. and Van Paepegem, W. (2019). Consistent application of periodic boundary conditions in implicit and explicit finite element simulations of damage in composites. Compos. Part B Eng., 168, 254-266. https://doi.org/10.1016/j.compositesb.2018.12.023

[18] Žmindák M. and Dudinský, M. (2012). Computational modelling of composite materials reinforced by glass fibers. Procedia Eng., 48, 701-710.

https://doi.org/10.1016/j.proeng.2012.09.573

[19] Srivastava V. K. and Lal, S. (1991). Mechanical properties of E-glass fibre reinforced nylon 6/6 resin composites. J. Mater. Sci., 26(24), 6693-6698. https://doi.org/10.1007/BF02402662

[20] Pal B. and Riyazuddin Haseebuddin, M. (2012). Analytical estimation of elastic properties of polypropylene fiber matrix composite by finite element analysis. Adv. Mater. Phys. Chem., 02(01), 23-30. https://doi.org/10.4236/ampc.2012.21004 
[21] Mirkhalaf, S. M., Eggels, E. H., van Beurden, T. J. H., Larsson, F. and Fagerström, M. (2020). A finite element based orientation averaging method for predicting elastic properties of short fiber reinforced composites. Compos. Part B Eng., 202(June).

https://doi.org/10.1016/j.compositesb.2020.108388

[22] Sorini, C., Chattopadhyay, A. and Goldberg, R. K. (2016). Development of a subcell based modeling approach for modeling the architecturally dependent impact response of triaxially braided polymer matrix composites. Nasa/Tm-2016-219116, (July).

[23] Kimura, S., Koyanagi, J. and Kawada, H. (2006). Evaluation of inititation of the interfacial debonding in single fiber composite. Japan Soc. Mech. Eng., 49(3), 451-457. https://doi.org/10.1299/jsmea.49.451

[24] Velden, P. K. A.V. (2010). Isight design optimization methodologies. Appl. Met. Process. Simul., 22, 8-9.

[25] Tiwari, S., Koch, P., Fadel, G. and Deb, K. (2008). Amga. (July), 729. https://doi.org/10.1145/1389095.1389235

[26] Tam, D. K. Y., Ruan, S., Gao, P. and Yu, T. (2012). High-performance ballistic protection using polymer nanocomposites. Adv. Mil. Text. Pers. Equip., 213-237.

https://doi.org/10.1533/9780857095572.2.213 